\section{MAJOR BLEEDING RISK ASSESSMENT IN ATRIAL FIBRILLATION PATIENTS TAKING VITAMIN K ANTAGONISTS}

\author{
Fernando Pivatto Júnior ${ }^{1}$, André Luís Ferreira da Silva ${ }^{1}$, \\ Indira Valente Bezerra ${ }^{1}$, Leonardo Martins Pires ${ }^{1}$, \\ Luís Carlos Amon ${ }^{1}$, Marina Bergamini Blaya ${ }^{1}$, \\ Rafael Selbach Scheffel ${ }^{1}$
}

\begin{abstract}
Introduction: The use of risk scores for the assessment of major bleeding and stroke in patients with atrial fibrillation (AF) helps evaluate the risks and benefits of oral anticoagulation therapy. The aim of this study was to describe the percentage of patients receiving anticoagulants for non-valvular AF with a high risk of major bleeding based on the HAS-BLED score, as well as identify potential modifiable risk factors of bleeding and compare the risk of major bleeding with the risk of stroke.
\end{abstract}

Methods: Retrospective cohort study involving patients of the anticoagulation outpatient clinic of the Division of Internal Medicine at Hospital de Clínicas de Porto Alegre. Major bleeding risk was estimated based on the HAS-BLED score and stroke risk was determined using the $\mathrm{CHADS}_{2}$ and $\mathrm{CHA}_{2} \mathrm{DS}_{2}-\mathrm{VASc}$ scores.

Results: Sixty-three patients were investigated (mean age $74.3 \pm 10.9$ years). The median HAS-BLED score was 2 points, $19(30.2 \%)$ patients had a score $\geq 3$ (high risk). The most prevalent modifiable risk factors were labile TP/INR (36.5\%) and concomitant use of drugs $(30.2 \%)$. The absolute risk of major bleeding based on the HAS-BLED score was higher than the risk of stroke in three $(4.8 \%)$ and four $(6.3 \%)$ patients in comparison with the $\mathrm{CHADS}_{2}$ and $\mathrm{CHA}_{2} \mathrm{DS}_{2}$-VASc score, respectively.

Conclusions: We concluded that the percentage of patients with high risk of major bleeding is similar to the rate found in the national literature $(30.2 \%)$. In addition, the most prevalent modifiable risk factors in our cohort were labile TP/INR and concomitant drug use.

Keywords: Hemorrhage; stroke; atrial fibrillation; warfarin; phenprocoumon

Oral anticoagulant (OAC) therapy with vitamin $\mathrm{K}$ antagonists (VKAs) has been used for more than 50 years. There is solid evidence on its efficacy in preventing thromboembolic complications in different clinical settings, including patients with atrial fibrillation (AF) ${ }^{1}$. Nevertheless, the benefit of anticoagulation must be balanced against the risk of increased hemorrhage ${ }^{1}$.

Strategies of treatment individualization based on a trade-off between the treatment-related individual benefit and harm are facilitated by the availability of clinical tools to predict patients' risk. The $\mathrm{CHADS}_{2}$ and $\mathrm{CHA}_{2} \mathrm{DS}_{2}-\mathrm{VASc}$ scores are used to evaluate OAC therapy and identify those patients who will benefit from this intervention. These scores are clinical risk factor-based schemes to predict the risk of stroke in patients with $\mathrm{AF}^{2}$. In addition, the HAS-BLED score predicts the risk of bleeding, which is the major harm caused by OAC therapy ${ }^{3}$. Patients with a HAS-BLED score $\geq 3$ are at high risk of bleeding. Therefore, these patients should be treated with caution, being closely followed up ${ }^{4}$.

Bleeding events may have significant prognostic and management implications. These events may lead to discontinuation of treatment, long-term disability, or even death. The fear of hemorrhagic complications is one of the
Clin Biomed Res. 2015;35(2):99-103

1 Department of Internal Medicine, Hospital de Clínicas de Porto Alegre. Porto Alegre, RS, Brazil.

Corresponding author: Fernando Pivatto Júnior E-mail: fpivatto@gmail.com Department of Internal Medicine, Hospital de Clínicas de Porto Alegre Rua Ramiro Barcelos, 2350. 90035-903, Porto Alegre, RS, Brazil. 
main reasons why physicians may withhold OAC therapy in some patients ${ }^{1}$.

The aim of this study was to describe the percentage of patients receiving anticoagulants for non-valvular AF with a high risk of major bleeding based on the HAS-BLED score, as well as identify potential modifiable risk factors of bleeding and compare the risk of major bleeding with the risk of stroke.

\section{METHODS}

A retrospective cohort study was conducted including all patients with non-valvular AF on OAC with VKAs attending the anticoagulation outpatient clinic of the Division of Internal Medicine at the Hospital de Clínicas de Porto Alegre (HCPA). All patients who were seen at the clinic during three consecutive months (October to December 2010) were screened for inclusion in the study. We believe that the duration of the screening period was adequate because the patients attended the outpatient clinic for at most two months. Patients with valvular AF, i.e., with mitral stenosis or previous heart valve surgery, were excluded because the ischemic stroke predictive scores $\left(\mathrm{CHADS}_{2}\right.$ and $\mathrm{CHA}_{2} \mathrm{DS}_{2}$-VASc) do not include this disorders ${ }^{5,6}$. The patients who were lost to follow-up, died, or whose anticoagulation therapy was discontinued were included in our analysis.

We performed a retrospective review of outpatient visits, emergency visits, and hospitalizations from January to December 2011 based on the patients' electronic medical records. We assessed age, sex, left ventricular ejection fraction (LVEF), complex aortic plaque and history of transient ischemic attack (TIA), stroke, diabetes, peripheral artery disease, hypertension, myocardial infarction, and heart failure. Previous systemic embolism, combined use of antiplatelet agents, oral anticoagulant (warfarin or phenprocoumon), and number of prothrombin time/international normalized ratio (PT/INR) tests were also investigated. Patients were evaluated in terms of anticoagulation control (using PT/INR tests) and occurrence of adverse events (ischemic stroke, systemic embolism, or bleeding).

Major bleeding was defined as any bleeding requiring hospitalization and/or causing a decrease in hemoglobin level of more than $2 \mathrm{~g} / \mathrm{dL}$ and/or requiring blood transfusion ${ }^{7}$. Presence of chronic dialysis or renal transplantation or serum creatinine $\geq 200 \mu \mathrm{mol} / \mathrm{L}$ $(2.26 \mathrm{mg} / \mathrm{dL})$ was classified as abnormal kidney function ${ }^{7}$. Abnormal liver function was defined as chronic hepatic disease (e.g., cirrhosis) or biochemical evidence of significant hepatic derangement (e.g., bilirubin $>2 x$ upper limit of normal, in association with AST/ALT/ALP $>3 x$ upper limit of normal) ${ }^{7}$. Anemia was defined if hemoglobin was below $13.0 \mathrm{~g} / \mathrm{L}$ in men and $12.0 \mathrm{~g} / \mathrm{L}$ in women. Time in therapeutic range was calculated based on the percentage of PT/INR tests in a 2.0-3.0 range and the Rosendaal linear interpolation method ${ }^{9}$ using the INR-Day 0.2.1 software.

Major bleeding risk was calculated using the HAS-BLED score, an acronym for hypertension (uncontrolled, $>160 \mathrm{mmHg}$ systolic), abnormal renal/liver function ( 1 point for presence of renal or liver impairment, maximum 2 points), stroke (previous history, particularly lacunar), bleeding history (major) or predisposition (anemia), labile INR (time in therapeutic range $<60 \%$ ), elderly ( $>65$ years), drugs/alcohol concomitantly (antiplatelet agents, nonsteroidal anti-inflammatory drugs; 1 point for drugs plus 1 point for alcohol excess, maximum 2 points) ${ }^{7}$. Patients were classified as low risk if their score was 0 ; intermediate risk for score 1-2, and high risk for patients with score $\geq 3$.

The mean risk of ischemic stroke was calculated based on the risk factors included in the $\mathrm{CHADS}_{2}$ and $\mathrm{CHA}_{2} \mathrm{DS}_{2}$-VASc scores (low risk $=0$; intermediate risk $=1$; high risk $=\geq 2$ ). The $\mathrm{CHADS}_{2}$ score was calculated based on presence of cardiac failure, hypertension, age above 75 years, diabetes, and prior stroke or TIA as previously described ${ }^{5}$. The $\mathrm{CHA}_{2} \mathrm{DS}_{2}$-VASc score included age 65-74, female gender, vascular disease, and age 75 or older, and overweight, with 2 points $^{6}$. Transthoracic echocardiogram was used to estimate LVEF using the Simpson method in the presence of segmental changes or the Teichholz method in the absence of segmental changes. PT for determination of INR was performed at the Hematology Laboratory of the HCPA using a standard coagulation testing system (Siemens BCS).

Assuming a 95\% confidence level and a margin of error of 3.5, a sample size of 47 patients was calculated to estimate the outcome major bleeding (annual incidence of $1.5 \%)^{7}$. Our analysis was carried out in WinPepi, version 11.32. Descriptive data were reported as number (\%), mean \pm standard deviation (SD), and median. We used SPSS 15.0 for statistical analysis. The present study is a subanalysis of a previous study ${ }^{10}$ submitted and approved by the Research Ethics Committee at the HCPA.

\section{RESULTS}

During the study period, 137 patients were seen at the anticoagulation outpatient clinic. Of these, $63(46.0 \%)$ were receiving OAC therapy for non-valvular $\mathrm{AF}$ and were included in the study. During the follow-up period, eight patients did not complete the 1-year follow-up: five discontinued the use of OAC $(7.9 \%)$, 
two were lost to follow-up (3.2\%), and one died (1.6\%) of a cause unrelated to anticoagulation. Thus, of the 63 patients included in the study, 55 completed the 365-day follow-up period, and the other eight patients had a mean follow-up of 128.5 days. The demographic characteristics of the sample are shown in Table 1. The presence of complex aortic plaques was not included in Table 1 because only four patients $(6.3 \%)$ underwent transesophageal echocardiogram. In terms of risk of stroke, we found that our patients had a high risk for this outcome. Since patients with a score $\geq 2$ are considered high-risk patients, with an indication for anticoagulation according to the $\mathrm{CHADS}_{2}$ and $\mathrm{CHA}_{2} \mathrm{DS}_{2}$-VASc scores, 95.2 and $100 \%$ of our patients, respectively, were included in this risk category.

The 63 patients included in the present study underwent $738 \mathrm{PT} / \mathrm{INR}$ tests (mean 11.7 \pm 5.1 tests/patient). Of these, 395 tests (53.5\%) showed $\mathrm{PT} / \mathrm{INR}$ between 2.0 and 3.0. As to time in therapeutic range analyzed by the Rosendaal linear interpolation method, in $64.8 \%$ of the follow-up period, PT/INR remained between 2.0 and 2.9 ; and in $89.9 \%$ of the follow-up period, PT/INR was between 1.5 and 3.4.

The absolute risk of major bleeding based on the HAS-BLED score was classified as high risk in $30.2 \%$ of patients (table 2). Elderly was the most prevalent HAS-BLED component. In terms of other major bleeding risk factors, 21 (33.3\%) patients had predisposing factor (anemia), 19 (30.2\%) used

Table 1: Demographic characteristics of the sample.

\begin{tabular}{lc}
\hline \multicolumn{1}{c}{ Characteristics } & $\mathbf{n}=\mathbf{6 3}$ \\
\hline Age, mean $( \pm \mathrm{SD})$ & $74.3 \pm 10.9$ \\
Age $\geq 75$ years, $\mathrm{n}(\%)$ & $39(61.9)$ \\
Female, $\mathrm{n}(\%)$ & $31(49.2)$ \\
$\mathrm{CHADS}_{2}$, median (IQR) & $3(3-4)$ \\
$\mathrm{CHA}_{2} \mathrm{DS}_{2}-\mathrm{VASc}$, median (IQR) & $5(4-6)$ \\
HAS-BLED, median (IQR) & $2(1-3)$ \\
Use of warfarin, $\mathrm{n}(\%)$ & $62(98.4)$ \\
Hypertension, $\mathrm{n}(\%)$ & $62(98.4)$ \\
Heart failure, $\mathrm{n}(\%)$ & $42(66.7)$ \\
$\quad \%$ LVEF, mean ( \pm SD) & $56.1 \pm 12.3$ \\
$\quad$ LVEF < 40\%, $\mathrm{n}(\%)$ & $7(11.1)$ \\
Diabetes, $\mathrm{n}(\%)$ & $32(50.8)$ \\
Previous stroke, $\mathrm{n}(\%)$ & $20(31.7)$ \\
Associated use of ASA, $\mathrm{n}(\%)$ & $19(30.2)$ \\
Previous MI, $\mathrm{n}(\%)$ & $10(15.9)$ \\
Peripheral arterial disease, $\mathrm{n}(\%)$ & $10(15.9)$ \\
Previous systemic embolism, $\mathrm{n}(\%)$ & $4(6.3)$ \\
Previous TIA, $\mathrm{n}(\%)$ & $1(1.6)$ \\
\hline
\end{tabular}

SD: standard-deviation, IQR= Interquartile Range, LVEF: left ventricular ejection fraction, ASA: acetylsalicylic acid, MI: myocardial infarction, TIA: transient ischemic attack. concomitant drugs (acetylsalicylic acid was the only antiplatelet agent associated), no patients used chronically nonsteroidal anti-inflammatory drugs, two $(3.2 \%)$ patients had history of major bleeding, and one $(1.6 \%)$ patient was alcoholic. The most prevalent modifiable risk factors were labile TP/INR (36.5\%) and concomitant use of drugs $(30.2 \%)$; uncontrolled hypertension was detected only in $4.8 \%$ (figure 1 ). During the follow-up period, three $(4.8 \%)$ patients had a major bleeding event, all of them belonged to the high-risk group.

The absolute risk of major bleeding based on the HAS-BLED score was higher than the stroke risk in three $(4.8 \%)$ and four $(6.3 \%)$ patients in comparison with the $\mathrm{CHADS}_{2}$ and $\mathrm{CHA}_{2} \mathrm{DS}_{2}$-VASc score, respectively. A complete concordance between the risk categories was found in $33.3 \%$ (CHADS $/$ /HAS-BLED) and $30.1 \%\left(\mathrm{CHA}_{2} \mathrm{DS}_{2}-\mathrm{VASc} / \mathrm{HAS}-\mathrm{BLED}\right)$ of patients (tables 3 and 4 ).

Table 2: Major bleeding risk on the HAS-BLED score.

\begin{tabular}{ccl}
\hline $\begin{array}{c}\text { HAS-BLED } \\
\text { score }\end{array}$ & $\mathbf{n}(\%)$ & Major bleeding risk, $\mathbf{n ~ ( \% )}$ \\
\hline 0 & $4(6.4)$ & Low, 4 (6.3) \\
\hline 1 & $12(19.0)$ & Intermediate, 40 (63.5) \\
\hline 2 & $28(44.4)$ & High, 19 (30.2) \\
3 & $10(15.9)$ & \\
4 & $5(7.9)$ & \\
5 & $4(6.4)$ & \\
\hline
\end{tabular}

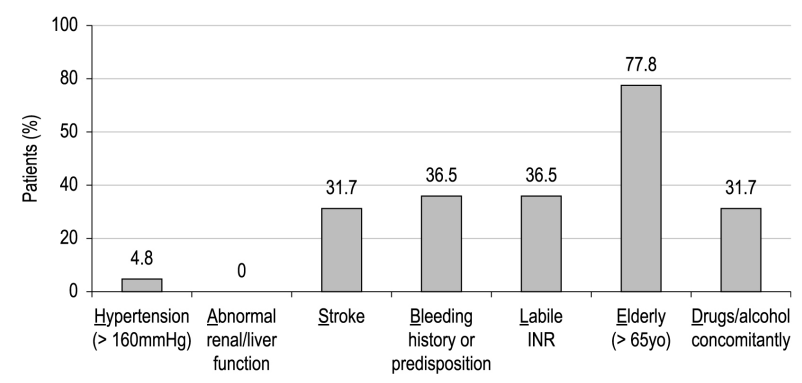

Figure 1: Prevalence of components of the HAS-BLED score.

Table 3: $\mathrm{CHADS}_{2}$ and HAS-BLED co-distribution according to the score-based risk categories.

\begin{tabular}{lcccc}
\hline \multicolumn{5}{c}{ HAS-BLED risk category } \\
\hline $\begin{array}{l}\text { CHADS }_{2} \text { risk } \\
\text { category }\end{array}$ & Low & Intermediate & High & $\mathbf{n ~ ( \% )}$ \\
\hline Low & 0 & 0 & 0 & $0(0)$ \\
Intermediate & 1 & 2 & 0 & $3(4.8)$ \\
High & 3 & 38 & 19 & $60(95.2)$ \\
$\mathrm{n}(\%)$ & $4(6.3)$ & $40(63.5 \%)$ & $19(30.2)$ & 63 \\
\hline
\end{tabular}


Table 4: $\mathrm{CHA}_{2} \mathrm{DS}_{2}-\mathrm{VASc}$ and HAS-BLED co-distribution according to the score-based risk categories.

\begin{tabular}{lcccc}
\hline \multicolumn{4}{c}{ HAS-BLED Risk Category } \\
\hline $\begin{array}{l}\mathrm{CHA}_{2} \mathrm{DS}_{2} \text {-VASc } \\
\text { risk category }\end{array}$ & Low & Intermediate & High & $\mathbf{n ( \% )}$ \\
\hline Low & 0 & 0 & 0 & $0(0)$ \\
Intermediate & 0 & 0 & 0 & $0(0)$ \\
High & 4 & 40 & 19 & $63(100)$ \\
$\mathrm{n}(\%)$ & $4(6.3)$ & $40(63.5)$ & $19(30.2)$ & 63 \\
\hline
\end{tabular}

\section{DISCUSSION}

The percentage of patients with high risk of major bleeding in the present study was $30.2 \%$. We found that labile TP/INR and concomitant drug use were the most prevalent modifiable risk factors. In addition, we found that the risk of major bleeding was higher than the risk of stroke in just $6.3 \%$ of patients. Because there are not national records of AF in Brazil, the rate of major bleeding risk we found was compared with similar values from other countries.

In a survey conducted in Denmark ${ }^{11}$ involving 44,771 non-valvular AF patients receiving OAC, 14,268 (31.9\%) were considered to have high bleeding risk, whereas in a Swedish nationwide cohort study ${ }^{12}$ of 170,291 non-valvular AF patients, 64,288 (37.8\%) were categorized as "high bleeding risk" based on the HAS-BLED score.

AF is usually asymptomatic and its first manifestation may be a devastating stroke. Individual assessment of risk of stroke and bleeding should be performed in patients who are candidates to receive OAC therapy so that appropriate stroke prevention can be offered. These risks should be discussed with the patient. The use of risk scores (such as the $\mathrm{CHA}_{2} \mathrm{DS}_{2}$-VASc and HAS-BLED) may help to inform the patient about the treatment strategy 4 .

Regarding bleeding risk, the availability of tools has helped clinicians to decide about the appropriate treatment, making it possible to assess the risks and benefits of the therapy. However, it is important to note that these bleeding risk tools should not be used to identify patients whose treatment needs to be discontinued. Conversely, these tools should be used to measure the patients' bleeding risk and determine appropriate risk reduction measures, i.e. treating modifiable risk factors (e.g.: anemia, drug use, alcohol use, uncontrolled hypertension, labile INRs) and providing support services to ensure close monitoring and regular review ${ }^{13}$. Thus, bleeding risk assessment with the HAS-BLED score should not be used as a justification not to prescribe OAC but rather to identify those patients who need more intense monitoring and education interventions ${ }^{4}$.

Because these thrombotic and bleeding risk scores share some risk factors, they are not expected to be independent. Nevertheless, the degree of their association has never been clearly determined until a recent study was conducted. In the study by Marcucci et al. with 3,920 patients, the authors found a correlation of 0.416 between the HAS-BLED and $\mathrm{CHADS}_{2}$ scores and a correlation of 0.512 between the HAS-BLED and $\mathrm{CHA}_{2} \mathrm{DS}_{2}-\mathrm{VASc}$ scores. The bleeding risk was equal to or lower than the cardioembolic risk in $89 \%$ (CHADS $/$ HAS-BLED) and $97 \%\left(\mathrm{CHA}_{2} \mathrm{DS}_{2}-\mathrm{VAS}_{\mathrm{c}} / \mathrm{HAS}-\mathrm{BLED}\right)$ of patients. Full agreement between the risk categories was found in $39.6 \%$ (CHADS $/$ /HAS-BLED) and $21.7 \%\left(\mathrm{CHA}_{2} \mathrm{DS}_{2}-\mathrm{VASC} / \mathrm{HAS}-\mathrm{BLED}\right)$ of patients. Conversely, $4.4 \%$ (CHADS 2 /HAS-BLED) and $7.7 \%$ $\left(\mathrm{CHA}_{2} \mathrm{DS}_{2}-\mathrm{VASc} / \mathrm{HAS}-\mathrm{BLED}\right)$ of patients had high cardioembolic risk/low bleeding risk or vice versa. There was a trend of increased frequency of stroke when there was increased bleeding risk within cardioembolic risk categories and vice versa. This finding showed that cardioembolic and bleeding risk classifications are correlated but not exchangeable. Therefore, a combined risk assessment is recommended instead of a strategy based only on cardioembolic risk evaluation ${ }^{2}$.

There are some limitations in our study. First, the retrospective design may have influenced the quality and consistency of the data collected. Besides, the patients' medical records included only events (cardiovascular and bleeding) that occurred at the HCPA or that were reported by the patients during clinical care. Second, the relative small sample size associated with the short follow-up period may have underestimated the occurrence of adverse events, especially events related to $A F$, which have a longer latency period. Third, none of the patients had abnormal renal/liver function, which affects major bleeding risk. Finally, the fact that the study was conducted at a single center may also be considered a limitation.

In conclusion, according to the HAS-BLED score, most patients using OAC for AF had intermediate or high risk of bleeding. Although the risk of bleeding should not exclude patients from OAC therapy, it may help to identify those patients who have to be more carefully managed and/or reviewed, in addition to highlighting the common correctable bleeding risk factors that may be addressed. Even in those patients with high bleeding risk, it is beneficial to provide them with OAC therapy because of their increased risk of stroke/thromboembolism ${ }^{14}$. The percentage of non-valvular AF patients categorized as "high bleeding risk" by the HAS-BLED score in our study was similar to the rates found in the literature. 


\section{REFERENCES}

1. Di Fusco SA, Colivicchi F, Santini $M$. The hemorrhagic risk: how to evaluate it. Pacing Clin Electrophysiol. 2013;36(10):1191-7. PMid:23663153.

2. Marcucci M, Lip GY, Nieuwlaat R, Pisters R, Crijns HJ, lorio A. Stroke and bleeding risk co-distribution in real-world patients with atrial fibrillation: the Euro Heart Survey. Am J Med. 2014;127(10):979-986. e2. http://dx.doi.org/10.1016/j. amjmed.2014.05.003. PMid:24838192.

3. Dzeshka MS, Lane DA, Lip GY. Stroke and bleeding risk in atrial fibrillation: navigating the alphabet soup of risk-score acronyms (CHADS2, CHA2 DS2 -VASc, R2 CHADS2, HAS-BLED, ATRIA, and more). Clin Cardiol. 2014;37(10):634-44. http://dx.doi.org/10.1002/clc.22294. PMid:25168181.

4. Lane DA, Lip GY. Use of the $\mathrm{CHA}(2) \mathrm{DS}(2)-\mathrm{VASc}$ and HASBLED scores to aid decision making for thromboprophylaxis in nonvalvular atrial fibrillation. Circulation. 2012;126(7):8605. http://dx.doi.org/10.1161/ CIRCULATIONAHA.111.060061. PMid:22891166.

5. Gage BF, Waterman AD, Shannon W, Boechler M, Rich MW, Radford MJ. Validation of clinical classification schemes for predicting stroke: results from the National Registry of Atrial Fibrillation. JAMA. 2001;285(22):286470. http://dx.doi.org/10.1001/ jama.285.22.2864. PMid:11401607.
6. Lip GY, Nieuwlaat R, Pisters R, Lane DA, Crijns HJ. Refining clinical risk stratification for predicting stroke and thromboembolism in atrial fibrillation using a novel risk factor-based approach: the euro heart survey on atrial fibrillation. Chest. 2010;137(2):263-72. http:// dx.doi.org/10.1378/chest.09-1584 . PMid:19762550.

7. Pisters $R$, Lane DA, Nieuwlaat $R$, de Vos CB, Crijns HJ, Lip GY. A novel user-friendly score (HASBLED) to assess 1-year risk of major bleeding in patients with atrial fibrillation: the Euro Heart Survey. Chest. 2010;138(5):1093-100. http:// dx.doi.org/10.1378/chest.10-0134. PMid:20299623.

8. World Health Organization (WHO). Department of Nutrition for Health and Development. Iron deficiency anaemia: assessment, prevention and control: a guide for programme managers. Geneva; 2001. [cited 2013 Sep 15].Available from: www.who.int.

9. Rosendaal FR, Cannegieter SC, van der Meer FJ, Briët E. A method to determine the optimal intensity of oral anticoagulant therapy. Thromb Haemost. 1993;69(3):236-9. PMid:8470047.

10. Pivatto Júnior $F$, da Silva $A L$, Simionato BM, Fuzinatto F, Oliveira $\mathrm{JC}$, Pires LM, et al. Management of anticoagulation with vitamin $\mathrm{K}$ antagonists in a tertiary hospital outpatient clinic. Clin Biomed Res. 2014;34(2):139-44.
11. Olesen JB, Lip GY, Hansen PR, Lindhardsen J, Ahlehoff O, Andersson $\mathrm{C}$, et al. Bleeding risk in 'real world' patients with atrial fibrillation: comparison of two established bleeding prediction schemes in a nationwide cohort. $J$ Thromb Haemost. 2011;9(8):14607. http://dx.doi.org/10.1111/j.15387836.2011.04378.x. PMid:21624047.

12. Friberg L, Rosenqvist M, Lip GY. Evaluation of risk stratification schemes for ischaemic stroke and bleeding in 182678 patients with atrial fibrillation: the Swedish Atrial Fibrillation cohort study. Eur Heart J. 2012;33(12):1500-10. http:// dx.doi.org/10.1093/eurheartj/ehr488. PMid:22246443.

13. Wang $Y$, Bajorek B. Safe use of antithrombotics for stroke prevention in atrial fibrillation: consideration of risk assessment tools to support decision-making. Ther Adv Drug Saf. 2014;5(1):21-37. http://dx.doi. org/10.1177/2042098613506592. PMid:25083260.

14. Roldán V, Marín F, Fernández $\mathrm{H}$, Manzano-Fernandez S, Gallego P, Valdés $M$, et al. Predictive value of the HAS-BLED and ATRIA bleeding scores for the risk of serious bleeding in a "real-world" population with atrial fibrillation receiving anticoagulant therapy. Chest. 2013;143(1):17984. http://dx.doi.org/10.1378/ chest.12-0608. PMid:22722228. 